\title{
Populismos autocráticos messiânicos na história recente das Américas ${ }^{12}$
}

\section{Autocratic messianic populisms in the Americas' recent History}

\section{Carlos de la Torre}

É professor titular do Center for Latin American Studies na Universidade da Flórida. Bolsista da Simon Guggenheim Foundation e pesquisador convidado do Woodrow Wilson Center for Scholars. Seus livros mais recentes incluem: Populisms: A Quick Immersion, 2019; The Routledge Handbook of Global Populism, 2019; De Velasco a Correa: Insurreciones, populismo y elecciones en Ecuador (2015), The Promise and Perils of Populism (2015), Latin American Populism of the Twenty First Century, co-editado com Cynthia Arnson (2013), e Populist Seduction in Latin America (2010).

\section{Tradução}

Joana Negri

Doutora em Comunicação pela Escola de Comunicação da UFRJ.

\footnotetext{
${ }^{1}$ Uma versão deste artigo foi apresentada como palestra anual de história da América Latina da The New School, co-patrocinada pelo The Americas Journal, 21 de abril de 2017. Agradeço a Federico Finchelstein e aos participantes da conferência por suas sugestões e comentários. Uma versão foi publicada anteriormente como "Populism Revived: Donald Trump and the Latin American Leftist Populists", The Americas Journal, 75 (4), p. 733-753, 2018.

${ }^{2}$ Neste artigo em particular, por uma escolha editorial, as referências bibliográficas foram todas incorporadas como notas de rodapé.
} 
RESUMO:

O século XXI poderá ser conhecido como o século do populismo. Não mais confinado à América Latina ou às margens da política européia, o populismo se espalhou pela África, Ásia e, com a eleição de Donald Trump, pelo berço da democracia liberal. Embora seja incerto qual o impacto que o populismo de Trump terá na democracia americana, vale a pena aprender com a América Latina, onde os populistas estiveram no poder desde as décadas de 1930 e 1940 até o presente. Mesmo enquanto populistas latino-americanos como Juan Perón e Hugo Chávez incluíam os pobres e os não-brancos na comunidade política, eles avançaram em direção ao autoritarismo, minando a democracia por dentro. Os fundamentos da democracia americana e as instituições da sociedade civil são fortes o suficiente para resistir ao populismo de direita do presidente Donald Trump? PALAVRAS-CHAVE: Populismo; América Latina; Donald Trump

\section{ABSTRACT:}

The twenty-first century could well become known as the populist century. No longer confined to Latin America or to the margins of European politics, populism has spread to Africa, Asia, and, with Donald Trump's election, to the cradle of liberal democracy. Even though it is uncertain what impact Trump's populism will have on American democracy, it is worth learning from Latin America, where populists have been in power from the 1930s and 1940s to the present. Even as Latin American populists like Juan Perón and Hugo Chávez included the poor and the nonwhite in the political community, they moved toward authoritarianism by undermining democracy from within. Are the foundations of American democracy and the institutions of civil society strong enough to resist US president Donald Trump's right-wing populism?

KEYWORDS: Populism; Latin America; Donald Trump

0 século XXI pode ser conhecido como o século populista. Não mais confinado à América Latina ou às margens da política europeia, o populismo se espalhou para a África, a Ásia e, com a eleição de Donald Trump, para o berço da democracia liberal ${ }^{3}$. Mesmo que seja incerto o impacto que o populismo de Trump

\footnotetext{
3 Para livros sobre populismo global, ver Francisco Panizza, ed., Populism and the Mirror of Democracy, (London: Verso, 2005); Carlos de la Torre ed., The Promises and Peril of Populism Global Perspectives, (Lexington: The University Press of Kentucky, 2015); Benjamin Moffitt, The Global Rise of Populism. Performance, Political Style, Representation, (Stanford: Stanford University Press, 2016); Ángel Rivero, Javier Zarzalejos, and Jorge del Palacio, eds., Geografías del
} 
terá sobre a democracia americana, vale a pena aprender com a América Latina, onde os populistas têm estado no poder desde as décadas de 1930 e 40 até o presente. Embora os populistas latino-americanos, como Juan Perón e Hugo Chávez, tenham incluído os pobres e os não-brancos na comunidade política, eles se aproximaram do autoritarismo ao minar a democracia a partir de dentro. Os fundamentos da democracia americana e as instituições da sociedade civil são fortes o suficiente para resistir ao populismo de direita de Trump?

Este ensaio compara experiências populistas de esquerda recentes na história da América Latina com a história mais recente do populismo de direita do Tea Party e de Trump nos EUA. Meu argumento está dividido em quatro seções. A primeira analisa como os acadêmicos interpretaram a relação entre populismo e democracia na América Latina e nos Estados Unidos. A segunda seção compara as rupturas populistas nas Américas. Enquanto o populista de esquerda latinoamericano rompeu com a ordem neoliberal e com a regra dos partidos políticos tradicionais, Trump prometeu derrubar o consenso multicultural neoliberal das elites dos partidos Republicano e Democrata. Jair Bolsonaro, por sua vez, formou uma coalizão de cristãos fundamentalistas que se opunham aos limitados direitos multiculturais das mulheres, dos não-brancos e das comunidades LGBTQ; demandavam lei e ordem; e proclamavam seu ódio ao Partido dos Trabalhadores. Em seguida, exploro diferentes construções da categoria povo e analiso como o conceito de povo é forjado para criar solidariedade entre os seguidores, enquanto um político é erigido como seu salvador. A última seção utiliza as experiências no poder de populistas latino-americanos de esquerda para especular sobre o futuro da democracia sob o domínio de Trump e Bolsonaro.

\section{Populismo, Democracia e Autoritarismo}

Populismo, (Madrid: Tecnos, 2017), Carlos de la Torre ed., The Routledge Handbook of Global Populism, New York: Routledge Press, 2019. 
Escrevendo após os traumas do fascismo, a primeira rodada de historiadores e cientistas sociais do populismo desconfiava das credenciais democráticas dos movimentos de massa que baseavam sua legitimidade em apelos ao povo. As noções de crise, as reações irracionais das massas ao estresse e a manipulação em condições de anomia estavam no centro das pesquisas nos campos da história e das ciências sociais. Analisando o macartismo, Talcott Parsons escreveu: "é uma generalização bem estabelecida nas ciências sociais que nem os indivíduos nem as sociedades podem sofrer grandes mudanças estruturais sem a probabilidade de produzir certa dose de comportamento 'irracional'"4 . As reações esperadas ao estresse, produzido pelas grandes transformações estruturais, foram a ansiedade, a agressão orientada ao que foi percebido como a fonte de tensão e o desejo de restabelecer uma fantasia onde tudo ficará bem - de preferência, como era antes da situação perturbadora.

Ao contrário da visão predominante do movimento populista norteamericano da década de 1890 como progressista e democratizante, o historiador Richard Hofstadter mostrou suas ambiguidades. Ele argumentou que os populistas "visavam remediar males genuínos, combinando fortes convicções morais com a escolha do ódio como uma espécie de credo"5. Os populistas pensavam a população como inocente, produtiva e vitimizada pelas elites predatórias. Suas visões de política, ele afirmou, "assumiram uma simplicidade ilusória"6. Era uma visão maniqueísta e conspiratória que atribuía "qualidades demoníacas a seus inimigos"7. 0 populismo foi o resultado de uma crise agrária e a "expressão de um estágio de transição" na história do capitalismo agrário ${ }^{8}$. Os populistas pretendiam restaurar uma idade de ouro e sua base de apoio era composta por

\footnotetext{
4 Talcott Parsons, "Social Strains in America" in Daniel Bell (ed.) The New American Right, (New York: Criterion Books 1959), p. 127.

${ }^{5}$ Richard Hofstadter, The Age of Reform, (New York: Alfred A. Knopf 1955), p. 20.

6 Ibidem, p. 65.

${ }^{7}$ Richard Hofstadter, "North America" in G. Ionescu and E. Gellner (eds) Populism: Its Meanings and National Characters, (New York: The Macmillan Company 1969), p. 18.

${ }^{8}$ Hofstadter, The Age of Reform, p. 95.
} 
aqueles que atingiram apenas um baixo nível de educação, cujo acesso à informação é pobre, e que são completamente excluídos do acesso aos centros de poder, dos quais se sentem completamente privados de autodefesa e sujeitos à manipulação ilimitada daqueles que detêm o poder9.

Embora ele tenha afirmado que o partido e movimento Populista não foi um precursor inequívoco dos movimentos autoritários modernos, “apesar de todas as suas franjas excêntricas"10, o estilo paranoico na política americana reapareceu com o macartismo e outras formas de "pseudo-conservadorismo"11. Esta opinião foi compartilhada por proeminentes cientistas sociais americanos, como Talcott Parsons, que argumentou que "os elementos de continuidade entre o populismo agrário ocidental e o macarthismo não são puramente fortuitos"12.

Gino Germani, um sociólogo nascido na Itália e que buscou refúgio das prisões de Mussolini na Argentina - apenas para perder seu emprego acadêmico sob o governo de Perón -, marcou a agenda de pesquisa dos estudos sobre o populismo latino-americano. Como Hofstadter, ele via o populismo como um estágio de transição provocado pela modernização da sociedade. Apoiando-se nas teorias da modernização e da sociedade de massa, ele argumentou que processos abruptos de modernização, como a urbanização e a industrialização, produziram massas em um estado de anomia que se tornaram disponíveis para mobilização de cima para baixo ${ }^{13}$. A base social do peronismo era a nova classe trabalhadora, composta de migrantes recentes que não eram socializados na cultura da classe trabalhadora e, portanto, podiam ser mobilizados de cima por um líder carismático.

A incorporação política das massas populares começou sob o totalitarismo. Este deu aos trabalhadores uma experiência de participação política e social em suas

\footnotetext{
9 Ibidem, p. 71.

10 Hofstadter, The Age of Reform, p. 71.

11 Richard Hofstadter, The Paranoid Style in American Politics and Other Essays, (New York: Alfred.

A. Knopf, 1965).

12 Parsons, "Social Strains in America”, p. 136.

13 Gino Germani, Política y Sociedad en una Epoca de Transición, (Buenos Aires: Editorial Paidos 1971), pp. 310-38.
} 
vidas pessoais, anulando, ao mesmo tempo, as organizações políticas e os direitos básicos que são os pilares de qualquer democracia genuína ${ }^{14}$.

Estudiosos demonstraram como o populismo da América Latina emergiu em sociedades oligárquicas, onde a franquia eleitoral era restrita, e como notáveis decidiram sobre os destinos políticos de suas nações, em contextos de extrema desigualdade, quando os pobres eram considerados uma ameaça perigosa e irracional à civilidade, ao progresso e à democracia. Sob esses sistemas de exploração e exclusão econômica, política e cultural, pessoas comuns eram humilhadas na vida cotidiana. Um trabalhador argentino entrevistado pelo historiador Daniel James relembrou a década de 1930 como uma época em que "sempre me sentia estranho quando ia à cidade, no centro de Buenos Aires - como se não pertencesse lá, o que era idiota, mas você sentia que eles lhe olhavam com desdém, sentia que você não estava vestido de forma adequada. A polícia lá também lhe tratava como um animal"15.

O populismo emergiu como uma força que prometia eleições livres para eliminar a fraude eleitoral, a incorporação socioeconômica dos trabalhadores e dos pobres, a soberania nacional e a dignidade simbólica dos excluídos. 0 populista transformou os estigmas por meio dos quais as elites costumavam desprezar os pobres em fontes de virtude. Nas décadas de 1930 e 1940, as elites de Buenos Aires usavam o termo cabecita negra para se referir à "pele escura e cabelos negros"16 dos migrantes internos. Eles racializavam os seguidores de Perón como "peronistas negros", ou como "grasita" ("oleosos", "sebentos"), evocando não apenas a sujeira e o óleo nos macacões dos trabalhadores, mas tudo o que é barato ou de mau gosto. Juan e Eva Perón transformaram as massas sem camisa

\footnotetext{
14 Germani, Política y Sociedad, p. 337.

15 Daniel James, Resistance and Integration. Peronism and the Argentine working class 1946-1976 (Cambridge: Cambridge University Press, 1988), p. 29.

16 Natalia Milanesio, "Peronists and Cabecitas. Stereotypes and Anxieties at the Peak of Social Change' in The New Cultural History of Peronism, eds. Matthew Karush and Oscar Chamosa, (Durham: Duke University Press, 2010), p. 55.
}

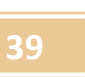


desprezadas pelas elites na personificação da nação argentina. Eva Perón, por exemplo, usou "o termo grasita para se referir carinhosamente aos pobres"17.

Uma vez no poder, populistas como Juan Perón, na Argentina, ou José María Velasco Ibarra, no Equador, aprovaram, simultaneamente, políticas para incorporar os excluídos e para restringir seus direitos civis fundamentais. Eles expandiram a franquia eleitoral, eliminaram a fraude eleitoral e ampliaram os direitos sociais. Sob Perón, em 1951, as mulheres conquistaram o direito de votar, e o comparecimento de eleitores durante seu primeiro governo cresceu de 18 para $50 \%$ da população ${ }^{18}$. Sob o primeiro governo de Perón, “a parcela do PIB nacional representada pelos salários aumentou de 37 para 47\%, enquanto os salários reais aumentaram 40\% entre 1946 e 1949"19.

Ao mesmo tempo, a democracia populista inclusiva também estava em desacordo com as noções de accountability e divisão de poder, e contornava os mecanismos de freios e contrapesos ${ }^{20}$. Os populistas construíram a noção de política como confronto contra inimigos que precisavam ser destruídos. Perón dizia que quando os adversários políticos se tornavam "inimigos da nação", eles não eram mais "cavalheiros com os quais se deveria lutar de maneira justa, mas cobras que se poderia matar de qualquer maneira"21. A lógica do confronto populista negava espaços democráticos para os opositores, construídos como inimigos dos pobres e da nação. Os setores da oposição, por sua vez, eram também antipluralistas, e negavam aos populistas qualquer legitimidade democrática. 0 historiador Luis Alberto Romero escreveu: "grande parte da oposição estava

\footnotetext{
17 Ibid, p. 57.

18 Mariano Plotkin, Mañana es San Perón. A Cultural History of Peron's Argentina, (Wilmington: Scholarly Resources, 2003), p. 165.

19 Mariano Plotkin, "Final Reflections", in The New Cultural History of Peronism eds. Matthew Karush and Oscar Chamosa, (Durham: Duke University Press, 2010), p. 273.

20 Enrique Peruzzotti, "Populism in Democratic Times: Populism, Representative Democracy, and the Debate on Democratic Deepening," in Latin American Populism in the Twenty-First Century, eds. Carlos de la Torre and Cynthia Arnson, (Baltimore and Washington, D.C.: Johns Hopkins University Press and Woodrow Wilson Center Press, 2013), p. 75.

${ }^{21}$ Federico Finchelstein, The Ideological Origins of the Dirty War (Oxford: Oxford University Press, 2014), 86.
} 
preocupada em eliminar Perón usando de todos os meios necessários"22. Perón, como outros populistas, foi deposto por um golpe de estado, em 1955. Velasco Ibarra, que foi presidente do Equador em cinco ocasiões, foi autorizado a terminar apenas um dos seus mandatos.

Hofstadter e Germani demonstraram, corretamente, a importância de analisar o populismo como simultaneamente inclusivo e autocrático. Os populistas desafiaram as exclusões e politizaram humilhações, ressentimentos e medos. No entanto, eles reduziram a complexidade da política democrática a uma luta entre dois campos antagônicos. O líder populista foi retratado como a personificação da vontade do povo homogêneo, e até mesmo como seu salvador e redentor, transformando a política em luta semelhante às religiosas. No entanto, apesar de todos os seus méritos, esses estudos pioneiros reduziram a política baseada em classes e interesses à alegada irracionalidade das massas, especialmente dos habitantes rurais pobres e dos migrantes recentes. Os estudiosos mostraram que a teoria da sociedade de massa considerava erroneamente os seguidores populistas como irracionais e o populismo como um estágio de transição na modernização da sociedade. "Desde o final dos anos 50, historiadores e outros estudiosos demoliram, persuasivamente, tanto o retrato dos primeiros populistas como fanáticos irracionais quanto a ideia de que aqueles que apoiavam o populismo estavam ligados demograficamente aos seguidores de McCarthy"23. 0 historiador Charles Postel mostrou que os populistas norte-americanos não estavam olhando para trás, mas eram modernos e defendiam seus interesses em um movimento que "se assemelhava a um tipo de democracia social reformista e evolucionária"24. 0 apoio dos trabalhadores argentinos a Perón era racional, porque, como secretário

\footnotetext{
${ }^{22}$ Luis Alberto Romero, A History of Argentina, (University Park: Pennsylvania State University Press, 2002), p. 124.

${ }^{23}$ Michael Kazin, The Populist Persuasion. An American History, (Ithaca: Cornell University Press, 1995), p. 192.

${ }^{24}$ Charles Postel, "The American Populist and anti-Populist Legacy" in John Abromeit, Bridget Cherston, Gary Marotta, and York Norman, (eds) Transformations of Populism in Europe and the Americas: History and Recent Tendencies, (London: Bloomsbury Press 2016), p. 119.
} 
do Trabalho, ele contemplava as demandas dos trabalhadores por seguridade social, legislação trabalhista e salários mais altos ${ }^{25}$.

Afastando-me de perspectivas sobre a sociedade de massa que reduzem o populismo à irracionalidade das massas em estado de anomia, baseei-me em historiadores e cientistas sociais que o entendiam como simultaneamente autocrático e inclusivo. Entendo o populismo como uma retórica maniqueísta que coloca o povo contra as elites. A noção de "povo" incorpora a ideia de conflito antagônico entre dois grupos, com a visão romântica da pureza da população excluída, entendida como "o povo". Aqueles que não concordam com sua interpretação da vontade popular são retratados como seus inimigos. Ao contrário de adversários, que lutam de acordo com um conjunto compartilhado de regras e cujas posições podem ser aceitas, os inimigos representam uma ameaça que deve ser contida. Os populistas consideram que uma parte da população, os excluídos, representam as pessoas reais e puras. Os populistas não concebem a política a partir de noções autolimitadoras, nem aceitam os limites das instituições e normas existentes. Seu objetivo é romper instituições que excluem o povo para criar uma nova ordem ${ }^{26}$.

Sob o populismo, um líder age como se ele ou ela personificasse a vontade do povo e pudesse conduzi-lo à redenção. Os populistas concentram poder e reduzem os espaços institucionais da oposição sob os pressupostos de que os inimigos conspiram constantemente, e que seu governo precisará permanecer no poder até que o trabalho de transformar o estado e a sociedade seja concluído. Perón se gabou de garantir sessenta anos de poder peronista ${ }^{27}$, e apenas o câncer impediu que Chávez se tornasse presidente permanentemente eleito da Venezuela. Os populistas veem a presidência como uma posse que deve permanecer em suas mãos até cumprirem a libertação de seu povo. No entanto, os populistas

\footnotetext{
25 Miguel Murmis, and Juan Carlos Portantiero, Estudio Sobre los Orígenes del Peronismo, (Buenos Aires: Siglo XXI 1971).

${ }^{26}$ Laclau, On Populist Reason (London and New York: Verso, 2005).

27 Finchelstein, Ideological Origins of the Dirty War, p. 92.
} 
reivindicam legitimidade ao ganhar eleições que poderiam perder e, assim, ficam sujeitos a resultados eleitorais ${ }^{28}$. 0 populismo, portanto, fundamenta sua legitimidade no preceito democrático de vitória eleitoral e na visão autocrática do poder como uma posse do líder. A contradição entre governar como se fossem a personificação do povo e pedir ao povo que aprove suas presidências em eleições abertas que poderiam ser perdidas explica suas ambiguidades em relação às instituições e práticas democráticas. Eles honravam as eleições livres de fraude, mas não podiam aceitar o pluralismo e assumiam que, uma vez que eram a personificação do povo, este votaria apenas neles. Os populistas não permitiam espaço para seus rivais, fabricados como inimigos conspiratórios e antinacionais que estavam tentando recuperar o poder para restabelecer o antigo regime. Assim, o populismo, simultaneamente, aceita a democracia e subverte-a para permanecer no poder até libertar o povo.

\section{Rupturas populistas nas Américas}

As narrativas populistas consideram a existência de arranjos institucionais impedimentos para o povo expressar sua voz e vontade. Como consequência, os populistas visam reformular o establishment prometendo devolver o poder ao povo. As rupturas populistas ocorreram quando a estrutura institucional da democracia estava em crise. Hugo Chávez, Evo Morales e Rafael Correa romperam o consenso da elite que ligava as políticas neoliberais às democracias eleitorais. Eles revisaram o neoliberalismo, promulgaram novas constituições e deslocaram as elites políticas tradicionais.

Venezuela, Bolívia e Equador passaram por grandes crises de representação política. Os partidos políticos eram percebidos como instrumentos de elites locais e estrangeiras que implementaram políticas neoliberais e, assim, aumentaram a

\footnotetext{
28 Isidoro Cheresky, El nuevo rostro de la democracia, (Buenos Aires: Fondo de Cultura Económica, 2015).
} 
desigualdade social. Partidos políticos tradicionais entraram em colapso quando outsiders políticos ascenderam ao poder, apoiados em plataformas que prometiam eliminar políticos corruptos; usar a constituição para reformular todas as instituições existentes; experimentar formas participativas de democracia; abandonar a ortodoxia neoliberal; e implementar políticas para redistribuir renda.

Um segundo fator que levou a rupturas populistas foi a antiga resistência popular generalizada ao neoliberalismo. Exemplos dessas insurreições populares contra o neoliberalismo foram a venezuelana Caracazo - uma insurreição maciça contra a alta no preço da gasolina que foi brutalmente reprimida com a morte de pelo menos 400 pessoas em fevereiro de 1989 -29; os movimentos maciços de resistência contra os três presidentes do Equador que tentaram implementar reformas estruturais neoliberais e foram impedidos de concluir seus mandatos entre 1997 e 200530; e o ciclo de protestos e tumultos políticos na Bolívia que resultou no colapso do sistema partidário, criado em 1985, e do modelo econômico neoliberal ${ }^{31}$.

Um terceiro fator que levou a rupturas populistas e à ascensão do populismo de esquerda na América Latina foi a percepção de que políticos e elites neoliberais haviam rendido a soberania nacional ao governo dos EUA e a instituições supranacionais como o Fundo Monetário Internacional. Esses líderes de esquerda propuseram um contraprojeto às iniciativas de comércio neoliberal dominadas pelos EUA. A Aliança Bolivariana para as Américas (ALBA) buscou uma integração real da América Latina e do Caribe, baseada na justiça social. Seus objetivos eram deter a dominação dos EUA na região, promovendo a unidade na América Latina, e criar um sistema internacional multipolar.

\footnotetext{
${ }^{29}$ Margarita López Maya and Alexandra Panzarelli, "Populism, Rentierism, and Socialism in the Twenty-First Century: The Case of Venezuela," in Latin American Populism in the Twenty First Century, ed. Carlos de la Tore and Cynthia Arnson (Baltimore and Washington: The Johns Hopkins University and the Woodrow Wilson Center Press, 2013), p. 244.

${ }^{30}$ Carlos de la Torre, Populist Seduction in Latin America, (Athens: Ohio University Press, second Edition, 2010), pp. 152-155.

${ }^{31}$ James Dunkerley, "Evo Morales, the 'Two Bolivias' and the Third Bolivian Revolution”, Journal of Latin American Studies 39 (2007), pp. 133-166.
} 
Nestor Kirchner chegou ao poder em 2003, em uma conjuntura que poderia ter levado a uma ruptura populista. Os partidos políticos estavam em crise, a Argentina acabara de passar por um profundo colapso econômico em 2001/02, e havia fortes movimentos de resistência ao neoliberalismo, à medida que os trabalhadores tomavam as fábricas e os desempregados ocupavam as ruas e saqueavam os supermercados. Apesar de usar uma linguagem populista de refundação, os Kirchner não estavam comprometidos com uma ruptura populista $^{32}$. Mas, mais importante, sua ambivalência em seguir o roteiro populista foi explicada pela forma como os movimentos sociais e a sociedade civil reagiram contra o que consideravam políticas e práticas autoritárias. Milhares de pessoas se mobilizaram contra as políticas agrárias de Cristina Kirchner. Suas tentativas de modificar a Constituição para permitir sua reeleição foram combatidas pela sociedade civil e por um tribunal constitucional independente. Em suma, instituições democráticas relativamente mais fortes e uma sociedade civil complexa foram impedimentos para uma ruptura populista na Argentina ${ }^{33}$.

Jair Bolsonaro foi eleito como consequência de uma grave crise econômica, escândalos maciços de corrupção da classe política e de uma crise de insegurança que levou à crise da legitimidade do regime ${ }^{34}$. Durante as presidências de Luiz Inácio Lula da Silva, popularmente conhecido como Lula (2003-2010), o Brasil alcançou altos níveis de crescimento econômico, e suas políticas sociais foram bem-sucedidas na redução da pobreza e na criação de uma nova classe média. No entanto, o colapso dos preços das commodities globalmente, durante o segundo mandato da sucessora de Lula, Dilma Roussef (2010-2016), conduziu à "pior

\footnotetext{
32 Enrique Peruzzotti, “'El kirchnerismo y la teoría política: la vision de Guillermo O’Donnell y Ernesto Laclau", In ¿Década Ganada? Evaluando el Kirchnerismo, edited by Carlos Gervasoni and Enrique Peruzzotti, (Buenos Aires: Debate, 2015), p. 400.

33 Oswaldo Iazeta,"Democracia y dramatización del conflicto en la Argentina kirchnerista (20032011)". In ¿Qué democracia en América Latina?, edited by Isidoro Chreresky, (Buenos Aires: CLACSO and Promoteo, 2012), p. 285.

34 Wendy Hunter and Timothy Power, "Bolsonaro and Brazil's Illiberal Backlash" Journal of Democracy 30 (1) 2019, 68-82.
} 
recessão da história brasileira". Nos dois anos seguintes, quase 8\% do PIB do Brasil - uma quantia quase igual ao PIB do Peru - desapareceu no $a^{35}$.

A classe política do Brasil esteve envolvida em escândalos de corrupção que levaram à prisão dos ex-presidentes Lula e Michel Temer. Um em cada três membros do Congresso foi indiciado ou está sob investigação por receber subornos de construtoras e/ou da estatal brasileira de petróleo. As administrações de esquerda de Lula e Roussef não conseguiram impedir uma onda de criminalidade que fez do Brasil uma das nações mais inseguras do mundo.

Em 2013, os cidadãos protestaram maciçamente contra o aumento dos preços do transporte público, os serviços precários das instituições do Estado e a corrupção. Manifestantes da classe média também descarregaram sua raiva contra o Partido dos Trabalhadores de Lula e Dilma. Alguns até expressaram nostalgia pelas políticas de lei e ordem da ditadura militar (1964-1985). Em 2016, comícios maciços exigiram o impeachment de Dilma Roussef, enquanto seu partido denunciava um golpe militar de direita e mobilizava seus seguidores. A presidente Roussef foi finalmente destituída do cargo em 2016. Seu impeachment, a corrupção em massa dos políticos e os clamores por segurança dos cidadãos abriram caminho para a eleição de um ex-oficial militar. Jair Bolsonaro, que serviu muitos anos no Congresso, foi apoiado por uma aliança de pentecostais, outros cristãos fundamentalistas e católicos de direita ${ }^{36}$.

A eleição de Bolsonaro pôs fim à regra dos partidos que levou à consolidação da democracia brasileira. Ele representou a rejeição de todos os partidos políticos - particularmente os de esquerda - e conquistou a presidência usando tropos misóginos, racistas e antidemocráticos. Por exemplo, quando votou contra a presidente Roussef, que foi torturada pelos militares, Bolsonaro dedicou

\footnotetext{
35 Ibid., 71.

${ }^{36}$ Lamia Oualalou, "Los evangélicos y el hermano Bolsonaro" Nueva Sociedad 280 (março-abril) 2019, 68-77.
} 
seu voto a seus torturadores. Ele se apresentou como um outsider, mas passou décadas em total mediocridade no Congresso Nacional.

A campanha eleitoral e a presidência de Donald Trump romperam o consenso de elite que ligava a globalização às políticas limitadas de reconhecimento multicultural para mulheres, não-brancos e comunidades LGBTQ $^{37}$. Ele prometeu revisar os acordos de livre comércio, trazer de volta empregos industriais e usou uma linguagem descaradamente racista contra os mexicanos e muçulmanos que questionavam as visões dos EUA como uma sociedade pós-racial. Ele era o herdeiro do Tea Party, uma insurreição da direita contra o primeiro presidente não-branco e suas limitadas políticas de redistribuição, como a assistência médica universal.

O Tea Party era composto por um conjunto de organizações de base, pela mídia de direita - especialmente a FOX News - e por elites que financiavam candidatos e ideias conservadoras ${ }^{38}$. Eles se opunham ao Obamacare e ao financiamento de hipotecas por considerá-los um ataque das elites liberais contra cidadãos que trabalhavam duro para doar esmolas aos pobres indignos. Foi também uma reação conservadora ao primeiro presidente não-branco. Obama era visto como um estrangeiro, "um invasor fingindo ser um americano... Suas conquistas acadêmicas e laços sociais o associaram à elite intelectual do país cujas (...) tendências cosmopolitas pareciam antipatrióticas"39. Donald Trump, um dos instigadores da teoria da conspiração que negava a veracidade do nascimento de Obama em solo americano exigia a divulgação da sua certidão de nascimento ${ }^{40}$, alcançou mais do que a base social do Tea Party, composta por conservadores

\footnotetext{
${ }^{37}$ Carlos de la Torre, “Trump's Populism: Lessons from Latin America, Postcolonial Studies 20 (02) 2017, 187-198 DOI: http://dx.doi.org/10.1080/13688790.2017.1363846

38 Theda Skocpol and Vanessa Williamson, The Tea Party and the Remaking of Republican Conservatism, (Oxford: Oxford University Press 2012), p. 190.

${ }^{39}$ Skocpol and Williamson, The Tea Party, p. 79.

40 Michael Barkun, A Culture of Conspiracy. Apocalyptic Visions in Contemporary America, (Berkeley: University of California Press, 2013), p. 187.
} 
brancos mais velhos, mais ricos e mais instruídos, apelando também à classe trabalhadora branca.

Em sua campanha, Trump desafiou alguns dos princípios fundamentais do neoliberalismo, como o livre comércio. Ele se opôs ao Nafta e ao acordo da Parceria Transpacífico. Ele relacionou o declínio nacional à ausência de produção industrial. Ele disse às multidões: "nós não ganhamos mais." "Não fazemos nada". "Estamos perdendo muito"41. Trump apontou o dedo para corporações como Ford, Apple, Nabisco e Carrier, por moverem suas fábricas para o exterior. Ele prometeu trazer empregos de manufatura para os EUA. Quando chegou ao poder, se envolveu em várias guerras comerciais e impôs tarifas.

A crítica nacionalista de Trump à globalização estava ligada à construção de imigrantes ilegais como "outros" parasitas. Em 2011, ele escreveu: "A imigração ilegal é uma bola de demolição destinada aos contribuintes dos EUA". Ele incitou as elites a lutarem por "Nós, o Povo, e não por grupos de interesse que querem mão de obra barata e um bloco de minorias capazes de causar bloqueios"42. Em seu livro intitulado "Grande Novamente: Como Consertar a América deficiente”, ele escreveu: "somos o único país no mundo cujo sistema de imigração coloca as necessidades de outras nações à frente das nossas". Ele argumentou que os governos estrangeiros incentivam a imigração ilegal "para se livrar de suas piores pessoas sem pagar qualquer preço por seu mau comportamento"43. Uma vez no poder, ele reprimiu imigrantes ilegais, separando crianças de seus pais e colocando bebês estrangeiros ilegais em gaiolas em centros de detenção.

Em sua campanha, ele usou tropos racistas contra muçulmanos e mexicanos, destruindo o mito de que os EUA estava se tornando uma sociedade pós-racista daltônica. As elites e muitos cidadãos acreditavam que a eleição de seu

\footnotetext{
41 Joseph Lowndes, "Populism in the 2016 U.S. election" in Matt Golder and Sona Golder, eds., Comparative Politics Newsletter, Vol. 26, (2), Fall 2016, p. 99.

42 John B. Judis, The Populist Explosion. How the Great Recession Transformed American and European Politics, (New York: Columbia Global Reports, 2016), p. 70.

43 David Smith, "Populism, Nationalism, and U.S. Foreign Policy", in Matt Golder and Sona Golder, eds., Comparative Politics Newsletter, Vol. 26, (2), Fall 2016, p. 104.
} 
primeiro presidente negro havia mostrado que os EUA estava adotando uma ordem pós-racial daltônica, que o racismo era coisa do passado e que os objetivos do movimento pelos direitos civis tinham sido alcançados. ${ }^{44}$ Ele lançou sua candidatura presidencial da Trump Tower, em Nova York, afirmando: "Quando o México envia seu povo, eles não estão enviando o que têm de melhor... Eles estão trazendo drogas. Eles estão trazendo o crime. Eles são estupradores. E alguns, suponho eu, são pessoas boas" 45 .

Ele expandiu sua plataforma racista chamando muçulmanos de terroristas e prometendo monitorá-los dentro dos EUA e banindo aqueles que quisessem entrar no país. Suas palavras anti-imigração racistas e xenófobas eram semelhantes às opiniões de muitos partidários do Tea Party. Eles viam os imigrantes ilegais como aproveitadores que estavam drenando os contribuintes dos EUA, usando serviços sociais e fundos do governo. Membros do Tea Party defenderam "restrições à cidadania da primogenitura, diminuição da liberdade de religião para os muçulmanos americanos e a suspensão das proteções presentes na Declaração de Direitos para suspeitos de terrorismo" 46.

Como os Tea Partiers, Trump não utilizou termos abertamente racistas, mas sim códigos, para descrever os afro-americanos como pessoas em desvantagem por causa de suas próprias falhas pessoais. As expressões hostis de Trump eram contra grupos militantes afro-americanos, como o "Black Lives Matter". O racismo populista de direita aberto contra os mexicanos - como atualmente todos os latinos são chamados nos EUA - é explicado pela visão duradoura dos mesmos como outros não nacionais e outsiders para a comunidade nacional ${ }^{47}$. Da mesma forma, os muçulmanos foram alvo, porque sua religião os torna estranhos ao cristianismo

\footnotetext{
${ }^{44}$ Michael Omi and Howard Winant, Racial Formation in the United States, (New York and London: Routledge, 2015), p. 257.

45 http://time.com/3923128/donald-trump-announcement-speech/

${ }^{46}$ Skocpol and Williamson 2012, p. 50.

${ }^{47}$ Suzanne Oboler, "Disposable Strangers: Mexican Americans, Racialization, and the Question of Latino/as' Belonging in the Era of Globalization" Unpublished paper delivered at the Conference Global Racism, University of Kentucky, Lexington, February 232013.
} 
americano. Em vez de repudiar os apoiadores da supremacia branca da KKK ou de outros grupos nacionalistas brancos, Trump abraçou-os, sinalizando que os afroamericanos também eram "membros de fora do grupo" 48 .

As elites multiculturais liberais eram retratadas como hipócritas e corruptas porque pretendiam obter mão de obra mexicana barata e transformar os hispânicos em seu bloco votante. Trump pretendia abolir o politicamente correto prometendo uma nova aurora, em que os homens brancos heterossexuais pudessem expressar livremente suas visões e opiniões. Ele disse, "o grande problema que este país tem é o politicamente correto" 49 . Alguns de seus fervorosos partidários brancos foram filmados gritando "Foda-se o politicamente correto" 50.

A mensagem de Trump fazia sentido para os sentimentos de ansiedade econômica e racismo dos eleitores brancos"51. Ele se tornou a voz dos "americanos brancos que se sentiam deixados para trás pela globalização e pela transição para uma economia pós-industrial"52. Sua base de apoio não era composta apenas por perdedores da globalização e homens brancos sem instrução. Os homens brancos da classe média também o apoiavam, pois muitos achavam que não estavam recebendo sua parcela e enfrentavam insegurança econômica em suas vidas. Eles achavam que mulheres, negros, hispânicos e gays eram fortalecidos por políticas injustas de ação afirmativa e correção política que visavam negativamente os homens heterossexuais brancos. Muitos

também se sentiam culturalmente marginalizados: suas visões sobre aborto, casamento gay, papéis de gênero, raça, armas e a bandeira confederada eram todas ridicularizadas na mídia nacional e vistas como atrasadas. E eles se sentiam parte

\footnotetext{
48 Arlie Russell Hochschild, Strangers in Their Own Land. A Journey to the Heart of Our Political Divide, (New York: The New Press, 2016), p. 226.

49 Joshua Green, Devil's Bargain. Steve Bannon, Donald Trump, and the Storming of the Presidency, New York: Penguin Press, 2017, 169.

50 http://www.nytimes.com/2016/08/04/us/politics/donald-trump-supporters.html

51 Katherine Cramer, "Listening to Rural Populist Support for Right-Leaning Candidates in the United States" in Matt Golder and Sona Golder, eds., Comparative Politics Newsletter, Vol. 26, (2), Fall 2016, 89.

52 Judis, The Populist, p. 75.
} 
de um declínio demográfico... Eles começaram a se sentir como uma minoria sitiada $^{53}$.

Trump, em suma, foi "o candidato da política de identidade para os homens brancos"54.

As rupturas populistas de esquerda na América Latina levaram ao abandono das políticas neoliberais. Chávez, Morales e Correa fortaleceram o Estado e o usaram para redistribuir a riqueza e reduzir a pobreza e a desigualdade. A Venezuela, a Bolívia e o Equador colheram enormes benefícios com o boom das commodities dos anos 2000, que elevou os preços do petróleo e do gás natural a níveis recordes. Como resultado do aumento das receitas, o investimento público e os gastos sociais dispararam, e as taxas de pobreza - e, em menor grau, a desigualdade - caíram, enquanto os preços do petróleo e de outras commodities estavam em alta ${ }^{55}$. Bolsonaro é um neoliberal extremo que quer trazer de volta um Brasil nostálgico, em que as mulheres, os não-brancos e as comunidades LGBTQ aceitam seus papéis subordinados na sociedade. Resta saber se Bolsonaro e Trump foram bem-sucedidos no desmantelamento das instituições e das políticas das últimas décadas que ligaram os mercados abertos e a globalização à limitada inclusão cultural das minorias, das mulheres e das comunidades LGBTQ.

\section{Construindo e forjando o conceito de povo}

“O povo" não é um dado primário; é uma construção discursiva e uma reivindicação feita em lutas entre políticos, ativistas e intelectuais. "O discurso populista não expressa simplesmente algum tipo de identidade popular; na

\footnotetext{
${ }^{53}$ Hochschild, Strangers in Their Own Land, p. 221.

${ }^{54}$ Hochschild, Strangers in Their Own Land, p. 230.

55 Carlos de la Torre and Cynthia Arnson, "Introduction. The Evolution of Latin American Populism and the Debates Over Its Meanings" in Latin American Populism in the Twenty First Century, ed. Carlos de la Tore and Cynthia Arnson (Baltimore and Washington: The Johns Hopkins University and the Woodrow Wilson Center Press, 2013), p. 12.
} 
verdade, ele constitui esta última"56. 0 povo pode ser construído com critérios étnicos ou políticos, e como uma população plural ou como um ator unitário.

Construções étnicas podem ser excludentes, quando os inimigos do povo são populações minoritárias como muçulmanos e não-brancos na Europa e nos EUA. "O povo" construído por Donald Trump enfrenta inimigos étnicos como muçulmanos, mexicanos ou militantes negros ativistas. Diferentemente da visão excludente de Trump do povo como branco, Evo Morales e seu partido político, o MAS, usou com sucesso os apelos etno-populistas inclusivos ${ }^{57}$. Dada a fluidez das relações raciais e étnicas na Bolívia, eles foram capazes de criar um partido étnico inclusivo baseado em organizações indígenas e movimentos sociais. O MAS e Morales tiveram sucesso porque também incorporaram organizações e candidatos mestiços. Morales retratou os povos indígenas como a essência da nação. 0 termo indígena foi politizado para incluir todos os bolivianos que defendiam a soberania nacional e os recursos naturais das elites neoliberais. Foi uma categoria abrangente que significou uma reivindicação à justiça pós-colonial e a um projeto político mais amplo de nacionalismo, autodeterminação e democratização ${ }^{58}$.

Bolsonaro é contra políticas e cotas de ação afirmativa que permitiram aos pobres e aos não-brancos frequentarem as universidades. Seus inimigos são aqueles que denunciaram o racismo e que implementaram cotas para reparar séculos de privilégios brancos institucionalizados. Além disso, para expandir a fronteira agrária, ele tem como alvo ativistas indígenas, ambientalistas e antropólogos que defendem os direitos indígenas. Bolsonaro assinou uma ordem executiva que permitiu ao Ministério da Agricultura, liderado por Tereza Cristina, delinear território indígena, limitando concessões feitas a indígenas brasileiros e

\footnotetext{
56 Ernesto Laclau, “'Populism: What's in a name?' in Francisco Panizza (ed.) Populism and the Mirror of Democracy, (London: Verso 2005), p. 48 emphasis in the original.

57 Raúl Madrid, The Rise of Ethnic Politics in Latin America, Cambridge: Cambridge University Press, 2012.

58 Andrew Canessa, "Todos somos indígenas: Toward a New Language of National Political Identity." Bulletin of Latin American Research 25, (2) 2006, 241-63.
} 
descendentes de escravos, conhecidos como quilombolas, enquanto impulsionava o agronegócio 59 .

Hugo Chávez e Rafael Correa articularam as construções políticas do povo. Chávez enquadrou a arena política para que ele não enfrentasse rivais políticos, mas sim uma oligarquia que ele definiu como o inimigo político do povo - "as elites que servem a si próprias e que trabalham contra a pátria"60. Da mesma forma, Correa enfrentou uma longa lista de inimigos políticos de seu governo, seu povo e sua nação. A lista incluía políticos tradicionais, donos da mídia privada, jornalistas, líderes de movimentos sociais autônomos, a "esquerda infantil" e quase todos os que questionavam suas políticas ${ }^{61}$.

Hugo Chávez, Rafael Correa e Donald Trump afirmaram “que eles e apenas eles representam o povo verdadeiro"62. Chávez, por exemplo, professou ser a personificação do povo venezuelano. Ele é citado alardeando: "Isto não é sobre Hugo Chávez; trata-se de um 'povo'. Eu represento claramente a voz e o coração de milhões"63. Em outra ocasião, Chávez ordenou: "Exijo lealdade absoluta a mim. Eu não sou um indivíduo, eu sou o povo"64. Aqueles que não pertencem ao povo são vistos como o estrangeiro, o antinacional e o Outro perigoso.

Diferentemente das construções autocráticas do povo como um só, Morales e o MAS tinham uma visão plural do povo. A Constituição de 2009 declarou a Bolívia como Estado plurinacional e comunitário. Ainda assim, por vezes, Morales tentou ser a única voz do povo. Quando os povos indígenas das planícies desafiaram suas políticas de extração mineral, eles foram desqualificados por

\footnotetext{
${ }^{59}$ https://www.as-coa.org/articles/tracking-first-100-days-brasil-president-jair-bolsonaro

60 José Pedro Zúquete, "The Missionary Politics of Hugo Chavez," Latin American Politics and Society 50, no. 1 (2008), p. 105.

61 Carlos de la Torre, “Correa un populista del siglo XXI,” in ¿Qué Democracia em América Latina? Ed. Isidoro Cheresky (Buenos Aires: CLACSO Prometeo, 2012), pp. 256-257.

62 Jan Werner Müller, What is Populism? (Philadelphia: University of Pennsylvania Press, 2016), p. 40.

63 Zúquete, "The Missionary Politics”, p. 100.

64 Luis Gómez Calcaño and Nancy Arenas, "El populismo chavista: autoritarismo electoral para amigos y enemigos," Cuadernos del CENDES 82 (2013), p. 20.
} 
terem sido manipulados por ONGs estrangeiras e não reconhecidos por serem autenticamente indígenas. Mas por causa do poder dos movimentos sociais, em cujo nome ele argumentava estar governando, Morales não conseguiu impor sua visão do povo como um só 65 .

O conceito de povo é forjado e incorporado em lutas e confrontos entre políticos que afirmam ser seus líderes e até mesmo salvadores contra aqueles construídos como inimigos. Apesar do uso inovador da televisão para criar espetáculos de mídia e de redes sociais como o Twitter, a campanha de Trump, assim como a de outros populistas, fez amplo uso de comícios em massa. Os comícios de Trump mostraram a seus seguidores - em sua maioria, brancos - que eles não eram mais uma "minoria sitiada". Um político que alegou representar seus interesses e identidades finalmente se dirigia a milhares de pessoas como eles. Como Trump disse, ele era o candidato dos "homens e mulheres esquecidos deste país", da classe trabalhadora e média branca66. Para aqueles que participaram de seus comícios, o próprio evento simboliza uma onda crescente ${ }^{67}$.

Rafael Correa, professor universitário de economia que virou político, utilizou de maneira criativa a televisão, a Internet e os comícios em massa. Em sua primeira tentativa à presidência, em 2006, ele misturou música e dança com discurso. Ele falou brevemente, apresentando uma ideia. Em seguida, a música foi tocada, e Correa e a multidão cantaram e dançaram junto com as músicas da campanha. Quando a música parou, Correa falou brevemente, seguido, de novo, de música, canções e dança. Essas inovações permitiram que as pessoas participassem e despertaram sentimentos de que, sob a liderança de Correa, todos os seus

\footnotetext{
${ }^{65}$ Nancy Postero, "El Pueblo Boliviano de Composición Plural. A look at Plurinationalism in Bolivia," in The Promise and Perils of Populism, ed. Carlos de la Torre (Lexington: Kentucky University Press, 2015), p. 422.

66 Scott Shane, "Combative Populist Steve Bannon Found his Man in Donald Trump" http://www.nytimes.com/2016/11/27/us/politics/steve-bannon-white-house.html

${ }^{67}$ Hochschild, Strangers in Their Own Land, 226.
}

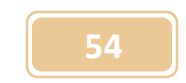


seguidores faziam parte de um projeto político comum, uma "revolução dos cidadãos" contra os políticos neoliberais ${ }^{68}$.

Os comícios populistas em massa são projetados para agradar os seguidores e fazê-los se sentirem bem. Trump, muitas vezes, disse ao seu público "vamos nos divertir esta noite". Os comícios em massa de Chávez eram frequentemente festas em que ele e seus seguidores dançavam e orgulhosamente ocupavam espaços públicos ${ }^{69}$. Chávez politizou desde os sentimentos de exclusão e raiva às humilhações que os pobres e os não-brancos têm que suportar na vida cotidiana.

Outros populistas usaram a violência para gerar solidariedade de grupo. Trump usou a violência racial verbal e física para marcar as fronteiras entre seu povo e os grupos externos, e para despertar paixões de raiva em seus comícios. A socióloga Arlie Horchschild relata algumas das palavras de Trump sobre o que fazer com aqueles que protestavam em seus comícios: "Eu gostaria de dar um soco na cara dele". "Acabe com ele. Eu prometo que pago as despesas legais"70. Em uma manifestação de campanha, Trump disse apontando para um crítico: "Há um remanescente que sobrou ali. Talvez seja melhor tirá-lo daqui. Tire o remanescente". A multidão, seguindo o exemplo, tentou eliminar outras pessoas que poderiam ser dissidentes, enquanto gritavam "EUA". O candidato interveio: "Isso não é mais divertido do que uma reunião chata?". ${ }^{71}$ Alguns apoiadores do Trump se sentiam autorizados a atacar os não brancos. Em Boston, por exemplo, dois homens brancos espancaram e urinaram em um homem latino desabrigado dizendo: "Trump estava certo; todos esses ilegais precisam ser deportados ". Em vez de denunciá-los, Trump justificou seu ataque, expressando que "pessoas que

\footnotetext{
68 de la Torre, Populist Seduction, 184.

${ }^{69}$ Carlos Carcione, "Como en abril del 2002" file:///Users/carlosdelatorre/Documents/chavismoelecciones/Como\%20en\%20Abril\%20del\%202002:\%20Ha\%20sucedido\%20otro $\% 2013 \% 20$ de $\% 20$ consecuencias\%20incalculables\%20\%20Por:\%20Carlos\%20Carcione.webarchive

${ }^{70}$ Hochschild, Strangers in Their Own Land, p. 224.

71 Timothy Snyder, On Tyranny. Twenty Lessons From the Twentieth Century, (New York: Tim Duggan Books, 2017), p. 45.
} 
estão me seguindo são muito apaixonadas. Eles amam este país e querem que este país seja grande novamente"72.

Reuniões populistas também pretendem transformar um líder em um personagem maior que a vida. Chávez foi erigido em um salvador que arriscou até a sua vida, liderando uma insurreição militar contra o presidente Carlos Andrés Pérez, em 1992. Em uma manifestação em julho de 1998, ao lançar sua candidatura, o ex-líder de um golpe de Estado foi transformado na personificação democrática ideal.

Chávez vestiu a sua característica boina vermelha de paraquedista e deu um soco no ar diante de uma multidão de dez mil torcedores... 'Vá em frente, me chame de líder do golpe', berrou ele. E, depois, acrescentou: 'Levante suas mãos se você acha que o golpe foi justificado'. Um mar de mãos se ergueu ${ }^{73}$.

Desde o início de sua campanha, Trump se referiu à sua extraordinária habilidade. "Precisamos de um líder verdadeiramente grande agora. Precisamos de um líder que escreveu The art of the deal... Precisamos de alguém que possa pegar a 'marca' dos Estados Unidos e torná-la grande novamente"74. 0 bilionário Donald Trump, mesmo não sendo "a solução perfeita para a América da classe alta"75, alegou representar o sonho do povo por mobilidade social. Ele ostentou sua riqueza; seu nome se tornou uma marca para arranha-céus, hotéis, cassinos e outras commodities; ele possuía a franquia Miss Universo; e foi uma celebridade da mídia. As pessoas, em seus comícios, disseram à etnógrafa Arlie Hochschild que estavam maravilhadas de "estar na presença de tal homem"76. Apesar de sua riqueza, ele era como as pessoas comuns, mas também incrivelmente superior a todas elas. Ele compartilhava seu gosto pela luta livre, mas diferentemente da

\footnotetext{
72 Lowndes, “Populism”, p. 100.

73 Bart Jones, ¡Hugo! Hanover (New Hampshire: Steerforth Press, 2007), 215-216.

${ }^{74}$ http://time.com/3923128/donald-trump-announcement-speech/

75 Judis, The Populist Explosion, p. 71.

76 Hochschild, Strangers, p. 226.
} 
maioria dos fãs, ele foi introduzido no WWE Hall of Fame em 2013 com as palavras "Donald Trump é uma instituição da 'WrestleMania'"77.

Como Juan Perón, Hugo Chávez, Bolsonaro e Rafael Correa, Trump personalizou a política e demonizou os inimigos ${ }^{78}$. Diferentemente de Hillary Clinton, que usou uma linguagem tecnocrática sofisticada para argumentar sobre a economia ou a política mundial, Trump recorreu a lugares comuns e generalidades. Para tornar a América grande novamente, ele argumentou que o necessário era um homem de negócios de sucesso e um empresário de cultura popular que não foi corrompido pelos acordos de políticos e lobistas. Ele mexeu com as emoções e foi capaz de construir a política como uma luta entre o bem, encarnado em sua persona, e o sistema corrupto, personificado por Hilary Clinton. Ela foi retratada como a personificação de tudo o que estava errado com a América. Por conseguinte, e sem um julgamento apropriado, Trump e seus seguidores a condenaram à prisão, cantando em seus comícios "Prendam ela!" Muitos orgulhosamente usavam camisetas ou carregavam cartazes que diziam " Hillary para a prisão".

Trump afirmou ser "alguém que poderia representar o que os americanos realmente pensam e, talvez mais importante, sentem"79. Um motociclista próTrump disse ao jornalista Ed Pilkington que Trump "fala o que pensa". Uma mulher, com as cores da bandeira americana em seu chapéu, manifestou que Trump falava do coração, e que diferentemente dos políticos profissionais, "Ele está no nosso nível. Ele fala de forma clara"80. 0 jornalista britânico Matt Taibbi relata que um jovem defensor da Pensilvânia disse a ele: "Quando Trump fala, eu

\footnotetext{
77 Aaron Oster, "Donald Trump and WWE. How the Road to the White House Began with Wrestlemani" http://www.rollingstone.com/sports/features/donald-trump-and-wwe-how-theroad-to-the-white-house-began-at-wrestlemania-20160201

78 Para exemplos de como os populistas na América Latina personalizam a política, ver de la Torre, Populist Seduction.

${ }^{79}$ Lowndes, "Populism", p. 99.

${ }^{80}$ Ed Pilkington, "Inside a Donald Trump Rally: Good People in a Feedback of Paranoia and Hate" https://www.theguardian.com/us-news/2016/oct/30/donald-trump-voters-rally-election-crowd
} 
realmente entendo o que ele está dizendo... Mas, quando a droga da Hillary Clinton fala, soa como um monte de besteira"81.

Similarmente aos populistas esquerdistas que confrontaram os partidos políticos tradicionais e a oligarquia, Bolsonaro e Trump confrontaram as elites políticas. Trump disse: "o establishment, a mídia, o interesse especial, os lobistas, os grandes doadores, todos eles são contra mim"82. Sua campanha televisiva final denuncia o "establishment político fracassado e corrupto" por ter entregado a soberania dos EUA para elites globais gananciosas que trouxeram "destruição para nossas fábricas". Com imagens das multidões predominantemente brancas que participaram de seus comícios, ele concluía: "A única coisa que pode parar esta máquina corrupta é você. Estou fazendo isso pelo povo e pelo movimento"83.

\section{Populistas no poder}

Na América Latina, o populista de esquerda incluía os excluídos, ao mesmo tempo em que minava a democracia a partir de dentro. Que lições podemos aprender da América Latina para especular sobre o futuro da democracia na América sob Trump e Bolsonaro? ${ }^{84}$

Em 1950, depois de reformar a constituição para permitir a reeleição de Perón, todas as instituições do governo estavam nas mãos do peronista. Perón “já havia substituído os membros do Supremo Tribunal de Justiça por defensores ferrenhos do regime, conquistado firme controle sobre o Congresso e dominado o movimento trabalhista"85. Como o historiador Luis Alberto Romero argumenta, "em todos os níveis de governo, todo o poder estava concentrado nas mãos do

\footnotetext{
81 Matt Taibbi, “Trump's Payback” Rolling Stone, (December 1, 2016), p. 38.

82 Judis, The Populist, p. 72.

83 https://www.youtube.com/watch?v=shqblcQW2RI

84 de la Torre, "Trump's Populism: Lessons from Latin America".

85 Mariano Plotkin, Mañana es San Perón, p. 98.
} 
executivo - seja prefeito, governador ou presidente -, deixando claro que o movimento e a nação eram considerados um só"86.

Da mesma forma, Chávez progressivamente ganhou o comando quase absoluto de todas as instituições do estado. Ele tinha uma supermaioria na legislatura e, em 2004, colocou a mais alta autoridade judicial, o Supremo Tribunal de Justiça, nas mãos de juízes leais. Centenas de juízes de primeira instância foram demitidos e substituídos por simpatizantes incondicionais ${ }^{87}$. 0 Conselho Nacional Eleitoral foi politizado. Mesmo assegurando que o momento da votação fosse limpo e livre de fraudes, este não impôs regras durante o processo eleitoral, que favorecia rotineiramente Chávez e seus candidatos. Rafael Correa também colocou seguidores leais no comando do poder eleitoral, do sistema judicial, do conselho eleitoral e de todas as instituições de accountability, como a Ouvidoria e a Controladoria 88 .

Para impor sua versão da realidade como a única verdade permitida, Chávez e Correa criaram leis para controlar o conteúdo que a mídia privada poderia publicar ou transmitir. Em 2000, a Lei Orgânica das Telecomunicações permitiu que o governo de Chávez suspendesse ou revogasse as concessões de radiodifusão para estabelecimentos privados quando fosse "conveniente para o interesse da nação"89. Rafael Corrêa promulgou, em 2013, uma lei de comunicação que criou instituições governamentais encarregadas de monitorar e regulamentar o conteúdo que a mídia poderia publicar. Esses presidentes tomaram estações de rádio e televisão dos críticos. Sob Chávez, o estado venezuelano tornou-se o principal comunicador, controlando $64 \%$ dos canais de televisão ${ }^{90}$. Correa criou

\footnotetext{
86 Luis Alberto Romero, A History of Argentina, p. 110.

87 Kirk Hawkins, "Responding to Radical Populism: Chavism in Venezuela", Democratization July, 2015 , p. 11.

88 Carlos de la Torre and Andrés Ortiz Lemos, "Populist Polarization and the Slow Death of Democracy in Ecuador", Democratization, 23, no2 (2016), p. 225.

${ }^{89}$ Javier Corrales, “Autocratic Legalism in Venezuela” Journal of Democracy 26, no2 (2015), p. 39.

90 Corrales, “Autocratic Legalism”, p. 41.
} 
um conglomerado de mídia estatal que incluía as duas estações de TV mais assistidas no Equador, bem como várias estações de rádio e jornais ${ }^{91}$.

Chávez e Correa sufocaram a mídia privada, diminuindo o montante dedicado a propaganda estatal investido em meios de comunicação críticos e manipulando os subsídios de modo a afetar o preço do papel ${ }^{92}$. Eles usaram o legalismo discriminatório, entendido como o uso da autoridade legal formal de maneiras discricionárias para processar, assediar e intimidar jornalistas e proprietários de mídia privada ${ }^{93}$.

As administrações populistas regulamentaram o trabalho de organizações não-governamentais (ONGs). Na Venezuela, ONGs que defendiam direitos políticos ou monitoravam o desempenho de órgãos públicos foram proibidas de receber assistência internacional ${ }^{94}$. Correa promulgou legislação que conferiu ao governo autoridade para penalizar ONGs que se engajassem na política ou interferissem nas políticas públicas de uma forma que violasse a segurança interna e externa ou perturbasse a paz pública. Para dar um exemplo, a organização ambientalista Pachama Alliance foi fechada por se desviar dos seus objetivos originais e interferir na política pública e na segurança95.

Para neutralizar o poder dos sindicatos de trabalhadores, professores sindicalizados, estudantes e grupos indígenas, movimentos sociais leais foram criados de cima para baixo. 0 protesto foi criminalizado nessas nações. Líderes sindicais e grevistas, mesmo quando eram simpatizantes de Chávez, foram

\footnotetext{
91 de la Torre and Ortiz Lemos, "Populist Polarization", p. 231.

92 Silvio Waisbord, Vox Populista, Medios, Periodismo, Democracia (Buenos Aires: Gedisa 2013).

93 Kurt Weyland, "The Threat form the Populist Left", Journal of Democracy Vol. 24, no 3, (July 2013), p. 23.

94 Javier Corrales, “Autrocratic”, p. 39.

95 de la Torre and Ortiz, "Populist Polarization”, pp. 229-230.
} 
acusados de terrorismo ${ }^{96}$. Centenas de ativistas camponeses e indígenas foram acusados de terrorismo e sabotagem no Equador ${ }^{97}$.

Diferentemente de antigas rupturas de democracia por meio de um golpe de Estado, Chávez e Correa aproximaram lentamente as democracias presidencialistas deficientes do autoritarismo. Esses líderes criaram regimes híbridos baseados em eleições em campos de disputa desequilibrados. Eles respeitavam algumas liberdades e instituições democráticas, ao mesmo tempo em que restringiam os direitos da oposição.

Quando Trump ganhou a eleição, a democracia nos EUA não estava em crise. Embora os cidadãos desconfiassem dos partidos e dos políticos tradicionais, o quadro institucional da democracia era robusto. A Constituição "separa a governança entre três ramos do governo, quebra a representação no tempo e no espaço (eleições escalonadas, sobreposição de unidades eleitorais), divide a soberania entre o governo nacional e os estados e filtra a expressão política em dois partidos"98. Sob essas restrições institucionais, é difícil encontrar o controle majoritário do governo tal qual na América Latina e, até a eleição de Trump, o populismo era confinado às margens do sistema político. Sob essa hipótese, a estrutura institucional da democracia e da sociedade civil dos EUA seria forte o suficiente para assimilar os desafios populistas sem grandes consequências desestabilizadoras ${ }^{99}$.

Um cenário alternativo plausível é que Trump - que chega à presidência quando o executivo tem mais poder sobre o legislativo, com o Senado e o Congresso nas mãos dos republicanos e com o poder de nomear ultraconservadores para o Supremo Tribunal e para os tribunais inferiores tentaria seguir o manual populista latino-americano de controle de todas as

\footnotetext{
96 Consuelo Iranzo,“Chávez y la política laboral en Venezuela 1999-2010.”Revista Trabajo 5, no8 (2011), pp. 28-31.

97 de la Torre and Ortiz Lemos, "Populist Polarization".

98 Lowndes, "Populism", p. 97.

99 Kurt Weyland and Raúl Madrid "Liberal democracy stronger than Trumpism so far" The American Interest Vol 13 nํㅜ, 2018
} 
instituições do estado. Ele colocou legalistas em posições-chave de poder. Ele ameaçou republicanos que não o apoiaram de todo o coração e está transformando o Partido Republicano - um partido para o qual ele não tem nenhuma lealdade duradoura - em seu foro personalista ${ }^{100}$.

Trump não gosta da mídia. Mas, ao mesmo tempo, a mídia e ser falado na mídia é tudo o que importa para ele. 0 mundo é uma tela para o seu rosto. Em seus comícios, ele levou seus seguidores a interceptar jornalistas que estavam sentados em uma seção separada. Ele ameaçou usar difamação e processar os jornais. Depois de assumir o poder, ele twittou que o New York Times, a NBC, a ABC, a CBS e a CNN eram os "inimigos do povo americano"101. Suas políticas de deportação em massa, paradas e revistas em bairros pobres e predominantemente negros e latinos, vigilância a muçulmanos americanos e revogação de direitos de gênero e LGBTs levariam a confrontos com organizações civis e de direitos humanos.

Mesmo que a estrutura institucional da democracia não desmorone sob Trump, ele já prejudicou a esfera pública democrática. 0 discurso de ódio e a difamação de minorias estão substituindo as políticas de reconhecimento e tolerância cultural construídas pelas lutas de movimentos feministas e antirracistas desde a década de 1960. Os potenciais ataques progressivos de Trump às liberdades civis e aos direitos humanos e os confrontos com a mídia, como na Venezuela e no Equador, desfigurariam a democracia ${ }^{102 .}$

\section{Conclusões}

Este ensaio mostrou como diferentes construções do povo podem levar a formas autocráticas de populismo. 0 populismo americano de direita

\footnotetext{
100 Joshua Green, Devil's Bargain, 190.

${ }^{101}$ https://www.washingtonpost.com/news/post-politics/wp/2017/02/17/trump-calls-themedia-the-enemy-of-the-american-people/?utm_term $=.099 \mathrm{~b} 48375 \mathrm{f} 77$

102 Nadia Urbinati, Democracy Disfigured. Opinion, Truth, and the People. (Cambridge, Harvard Univeristy Press, 2014).
} 
contemporâneo baseia-se em retratos étnicos do povo e em construções racistas e xenofóbicas dos outros grupos sociais. Eles também veem o povo como uma coletividade unitária ameaçada por estrangeiros não brancos e / ou muçulmanos. Populistas de direita, como Trump ou Bolsonaro, não prometem mais democracia. Eles estão olhando para trás e querem restaurar um passado excludente glorioso e imaginário.

Os exemplos de Chávez e Correa mostram que as promessas populistas de redenção, feitas em nome de um povo unitário, terminaram em autoritarismo. Nessas nações, o populismo populista não restringia apenas os direitos e liberdades da oligarquia, da direita ou das classes altas. Chávez e Correa silenciaram, cooptaram e reprimiram movimentos sociais críticos, ONGs e partidos de esquerda. Eles usaram o legalismo discriminatório para silenciar os críticos e minaram as liberdades e direitos que permitiriam aos movimentos sociais impulsionarem suas demandas. Os populistas não obliteraram a democracia. Criaram regimes híbridos que preservaram algumas liberdades democráticas, como as eleições, e regulamentaram, sem dominar totalmente, a sociedade civil e a esfera pública. Seu hibridismo significava que alguns espaços institucionais poderiam ser usados para resistir às tentativas do líder de criar a fantasia do povo como um só.

Chávez e Correa tentaram construir o povo como uma entidade homogênea cuja vontade eles alegavam personificar. Morales e seu partido político, o MAS, diferia desses construtos autocráticos por ter uma visão mais plural do povo. Morales, por vezes, tentou seguir o manual populista tentando ser a única e verdadeira voz de todos os bolivianos, mas poderosos movimentos sociais usaram a noção de que eles eram a voz do povo para desafiar Morales. 
Os populistas no poder atacam as instituições que são "um baluarte indispensável contra o despotismo político"103. 0 constitucionalismo, a separação de poderes, a liberdade de expressão, de reunião e de imprensa são necessários à política de democracia participativa, ao fortalecimento da esfera pública e ao avanço das demandas democratizantes dos movimentos sociais. Os populistas no poder, mesmo aqueles que prometeram mais democracia e o fim do neoliberalismo, visaram precisamente a estrutura constitucional da democracia. No início, o populista erodiu a democracia usando procedimentos democráticos e ferramentas, como as eleições, para fins antidemocráticos. No final, seus ataques sistemáticos aos direitos e às liberdades civis, suas tentativas de controlar e cooptar a sociedade civil e a esfera pública empurraram as democracias em crise para o autoritarismo. Democracias mais institucionalizadas não estão imunes aos desafios autocráticos populistas. Como na Argentina de Perón ou nas nações bolivarianas, a política de polarização populista de Trump está corroendo as possibilidades de diálogos e compromissos democráticos. Ele já desfigurou a esfera pública democrática e tolerante, normalizando o sexismo, o discurso do ódio, a xenofobia e o racismo. 0 futuro das instituições democráticas é incerto sob Trump.

Talvez seja cedo para falar de uma nova onda populista na América Latina. Mas, com exceção do México, onde o esquerdista Manuel López Obrador está no poder, parece que, como na maior parte do mundo, o populismo de direita também está em ascensão na América Latina. Como no Brasil, em vários países latinoamericanos há círculos eleitorais amplos que se ressentem das políticas limitadas de reconhecimento multicultural para comunidades LGBTQ, mulheres e nãobrancos. Cristãos fundamentalistas estão se tornando ativos na política e estão à procura de uma oportunidade para restabelecer as visões tradicionais da família cristã heterossexual. As diásporas venezuelanas e, em menor grau, haitianas estão criando sentimentos xenófobos e até mesmo ações coletivas contra os imigrantes. Bandidos atacaram imigrantes venezuelanos e queimaram seus pertences na

103 Richard Wolin, “The Disoriented Left: A Critique of Left Schmittianism” in Richard Wolin, The Frankfurt School Revisited (New York and London: Routledge 2006), p. 251. 
cidade de Ibarra, no norte do Equador, por exemplo ${ }^{104}$. Os vencedores de direita poderiam politizar as demandas de lei e ordem contra o crime e a insegurança. Como no Brasil, uma aliança multiclasse, apoiada em conservadorismo cultural e xenofobia e demandando lei e ordem, pode ser articulada sob a figura de um outsider que promete acabar com a corrupção e com os imigrantes que estão tirando empregos, e também dar fim às agressões à família promovidas por feministas e ativistas LGTBQ.

104 https://www.theguardian.com/world/2019/jan/21/ecuador-targets-venezuelan-migrantsafter-womans-death. 